\title{
Antibiotic therapy reduces nitrosative stress and programmed cell death in the rabbit foetal lung
}

\author{
C. Gras-Le Guen**\#, A. Jarry ${ }^{\Uparrow}$, G. Vallette ${ }^{\top}$, C. Toquet ${ }^{\top,+}$, C. Colombeix ${ }^{\S}$, \\ C.L. Laboisse ${ }^{\uparrow,+}$, G. Potel*, J-C. Roze ${ }^{\#}$, D. Bugnon* and T. Debillon ${ }^{\#}$
}

ABSTRACT: The correlation of clinical and epidemiological data suggests that intrauterine infection/inflammation can promote foetal lung injury.

The aim of this study was: 1) to characterise the early inflammatory response elicited in infected foetal lungs, in terms of nitric oxide-derived oxidative stress and programmed cell death; and 2) to investigate the effects of antibiotic therapy on these parameters.

A previously described rabbit experimental model of materno-foetal infection was used. Animals were divided into three groups: controls; Escherichia coli infected (12 h); and E. Coli infected (12 h) and treated (24 h gentamicin+ceftriaxone). Foetal lungs were examined in terms of histology, nitric oxide synthase (NOS) activity, immunohistochemical detection of 3-nitrotyrosine, and detection of apoptotic cells by the TUNEL assay and Hoechst staining.

In the infected group, a moderate inflammatory response was observed, associated with a significant increase in inducible NOS activity, the formation of 3-nitrotyrosine residues in epithelial and immune cells, the down-regulation of constitutive NOS activity and clusters of apoptotic cells, as compared with the control group. Early antibiotic therapy, initiated at $12 \mathrm{~h}$ postinoculation, elicited a significant decrease in the infection-induced nitrosative stress. Levels of 3nitrotyrosine and of apoptotic cells were decreased in the infected-and-treated group compared with the infected group, mainly by the re-expression of constitutive NOS and of the basal level of inducible NOS.

Altogether, these findings indicate that early antibiotic therapy can curb the inflammatory reaction and help avert antenatal lung injury, which is known to be involved in the onset of bronchopulmonary dysplasia.

KEYWORDS: Antenatal lung inflammation, antibiotic therapy, intrauterine infection, nitric oxide synthase, oxidative stress

$\mathbf{R}$ ecent reports have suggested that intrauterine infection/inflammation leading to pre-term delivery can promote foetal lung injury [1-3]. Epidemiological data and some clinical associations indicate that the development of neonatal bronchopulmonary dysplasia (BPD), defined as the continued requirement for supplemental oxygen beyond 36 weeks postmenstrual age [4-6], is multifactorial and involves a variety of causative factors, such as supplemental oxygen and the use of prolonged mechanical ventilation [7]. However, chorioamnionitis [8], associated with oxidative stress [9], apoptosis [10] and foetal inflammatory response $[11,12]$, is also regarded as a cause of BPD [2], although the hierarchy of events leading to lung injury in BPD is still not clearly established.
Recent studies point to oxidative stress as an important component leading to lung injury [9, 13]. Oxidative stress results from the formation of both: 1) reactive oxygen species (ROS), such as superoxide and hydrogen peroxide, which can be scavenged by superoxide dismutase and catalase latter, described more recently, consists of nitric oxide (NO) and its deleterious derivatives, such as peroxynitrite, which is involved in the nitration of protein tyrosine residues and, thus, in the formation of 3-nitrotyrosine [14-16]. NO originates from the conversion of L-arginine into Lcitrulline, in a reaction catalysed by NO synthase (NOS) [17]. Different NOS isoforms have been described: constitutive $\mathrm{Ca}^{2+}$-dependent isoforms (NOS1, NOS3), generating low amounts of NO; [14]; and 2) reactive nitrogen species (RNS). The
AFFILIATIONS

*Laboratoire d'Antibiothérapie Clinique et Expérimentale, Faculté de Médecine de Nantes,

\#Dépt de Périnatologie Hôpital Mère-Enfant, CHU de Nantes,

- Unité INSERM 539 Faculté de

Médecine de Nantes,

+Laboratoire d'Anatomie

Pathologique, CHU de Nantes, and

sIFR 26, CHU de Nantes, Nantes,

France.

CORRESPONDENCE

C. Gras-Le Guen

Laboratoire d'Antibiologie Clinique et

Expérimentale

Faculté de Médecine

1 rue G Veil

44035 Nantes

France

Fax: 33240412854

E-mail: christele.grasleguen@

chu-nantes.fr

Received:

March 82004

Accepted after revision:

August 12004

European Respiratory Journal

Print ISSN 0903-1936

Online ISSN 1399-3003 
and an inducible $\mathrm{Ca}^{2+}$-independent isoform (NOS2), generating high levels of $\mathrm{NO}$ and resulting in the formation of reactive nitrogen oxide species, e.g. peroxynitrite $\left(\mathrm{ONOO}^{-}\right)$[18]. Recent studies have shown that both ROS and RNS are implicated in the pathogenesis of BPD $[9,19,20]$.

Clinical practice to combat intrauterine infection consists of systematic maternal antibiotic treatment, which is still regarded as a controversial approach. In fact, the efficacy of antibiotic therapy has not yet been demonstrated in cases of declared intrauterine infection [21]. Preliminary studies in rabbit intrauterine-infection models have indicated that maternal antibiotic therapy improves the foetal survival rate, whereas foetal bacteraemia persist $[22,23]$. These studies raise the issue of the mechanisms by which antibiotics can protect against injury, especially in the lungs.

In this context, a newly developed experimental model of Escherichia coli materno-foetal infection in the rabbit has been used in combination with antibiotic therapy [23]. This model was found to be relevant to the clinical situation in terms of foeto-placenta unit, evolution and foetal response to antibiotic therapy, since maternal antibiotic therapy had a beneficial effect on foetal survival but was ineffective on foetal bacteraemia. The aim of the present study was: 1) to characterise the inflammatory response elicited in infected foetal lungs, in terms of NO-derived oxidative stress and programmed cell death; and 2) to study the effects of antibiotic therapy on these parameters.

\section{MATERIALS AND METHODS \\ Experimental model}

Micro-organism

The study was performed with the RS218 (O18: K1: H7) strain of $E$. coli K1, isolated from the central nervous system (cerebrospinal fluid) of a newborn. This bacterial strain has already been studied for virulence factors and invasion genes [24]. The minimal inhibitory concentration of this strain for ceftriaxone and gentamicin was 0.06 and $0.5 \mathrm{mg} \cdot \mathrm{L}^{-1}$, respectively.

Intrauterine inoculation

The intrauterine inoculation protocol, using a previously described model [23], was approved by the University of Nantes Experimental Therapy Department (Nantes, France). Fourteen female New Zealand White rabbits, weighing 3.7$4.5 \mathrm{~kg}$ (CEGAV, Saint Marc d'Egrenne, France), were obtained 10 days before the end of their usual 33-day gestation period, housed at the Nantes School of Medicine, and given water and antibiotic-free granules ad libitum. On day 28 of gestation, the animals were anaesthetised intramuscularly with $25 \mathrm{mg} \cdot \mathrm{kg}^{-1}$ ketamine. A laparotomy was then performed by means of a 2$\mathrm{cm}$ vertical incision along the median line below the gravid uterus. Once the uterus was exposed, a single injection of an inoculum E. coli $\left(1 \times 10^{6} \mathrm{CFU}\right.$ in $1 \mathrm{~mL}$ of $0.9 \% \mathrm{NaCl}$ solution $)$ or sterile vehicle alone was injected, under visual control, into one of the horns, facing a foeto-placenta unit, without more precise topographic localisation. The incision was then closed up level by level and the animals were returned to their cages.

\section{Maternal antibiotic treatment}

Mother rabbits $(n=14)$ were assigned to one of the following three groups: 1$)$ control animals $(n=4)$, inoculated with saline serum and sacrificed $12 \mathrm{~h}$ after inoculation; 2 ) infected animals $(\mathrm{n}=5)$, inoculated with E. coli and sacrificed $12 \mathrm{~h}$ afterwards; or 3) infected-and-treated animals $(n=5)$, inoculated with E. coli and treated with ceftriaxone (Rocephine ${ }^{\circledR}$; Roche, Meylan, France) and gentamicin (Gentamicin ${ }^{\circledR}$; Schering Plough, Levallois Perret, France) for $24 \mathrm{~h}$ (fig. 1). In the experimental model, intrauterine inoculation was chosen instead of ascending inoculation, even though this way is not physiological, because it gives the best yield, allowing intrauterine infection to be reproduced in $100 \%$ of animals. Treatment was initiated $12 \mathrm{~h}$ after intrauterine inoculation. To assess the antibiotic effect according to preliminary results (data not shown), treatment was initiated as early as $12 \mathrm{~h}$ after inoculation, at which time most infected foetuses were still alive and could benefit from the treatment. Both antibiotics were diluted in a $0.9 \% \mathrm{NaCl}$ solution for intravenous administration to mother rabbits through a catheter inserted into a marginal vein of the ear (each ear was used for an antibiotic). For both drugs, a computer-controlled variable infusion rate was delivered and adjusted, as previously reported [23, 25], in order to attain mother rabbit plasma concentrations mimicking the pharmacokinetics observed in humans after a single daily injection of the human-like dose of $1 \mathrm{~g} \cdot \mathrm{day}^{-1}$ ceftriaxone and $3 \mathrm{mg} \cdot \mathrm{kg}^{-1} \cdot \mathrm{day}^{-1}$ gentamicin. In order to compare these three groups with the spontaneous evolution of this intrauterine infection model, a previously described group of animals was used, who had been inoculated with $1 \times 10^{6} \mathrm{E}$. coli without any antibiotic treatment, in which $100 \%$ mortality was observed between 24 and $36 \mathrm{~h}$.

\section{Day $0 \quad$ Day 28 \\ Beginning of gestation Saline inoculation}
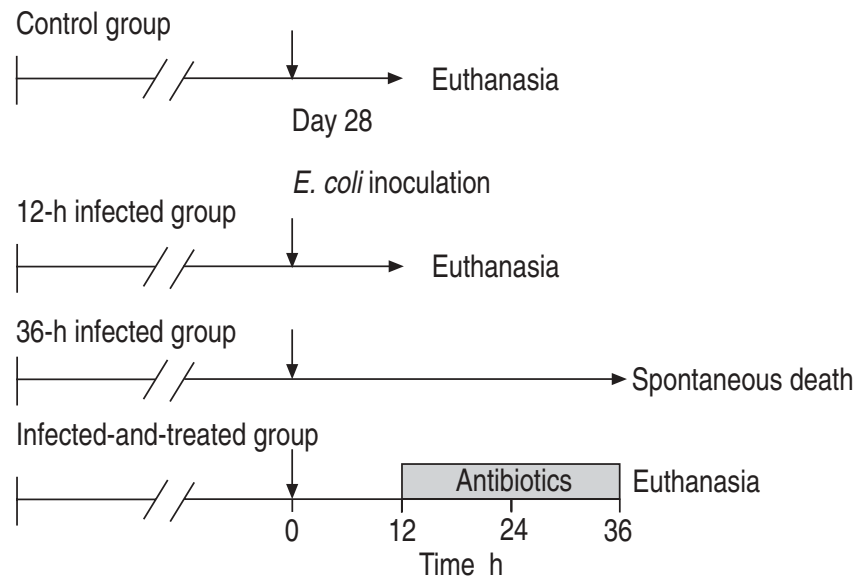

FIGURE 1. Experimental setup. Animals were inoculated with saline serum or $1 \times 10^{6}$ Escherichia coli on day 28 of gestation. Some foetuses were extracted $12 \mathrm{~h}$ after inoculation (control group and 12-h infected group), whereas some foetuses remained in utero as long as possible (36 h-infected group). Some foetuses were treated $12 \mathrm{~h}$ after inoculation with $24 \mathrm{~h}$ antibiotic therapy and extracted $36 \mathrm{~h}$ after inoculation (infected-and-treated group). 


\section{Euthanasia}

In untreated and control groups, mothers were killed $12 \mathrm{~h}$ after E. coli or $0.9 \% \mathrm{NaCl}$ solution inoculation, whereas animals treated with a 24-h antibiotic infusion were euthanised $36 \mathrm{~h}$ after inoculation. In all cases, mother rabbits were anaesthetised with propofol $\left(3 \mathrm{mg} \cdot \mathrm{kg}^{-1}\right)$ and foetuses were extracted by cesarean section. The survival rate was quantified and all animals were then killed by an overdose of sodium penthotal $\left(50 \mathrm{mg} \cdot \mathrm{kg}^{-1}\right)$. Blood was obtained by cardiac puncture only after the animals no longer blinked an eyelid or moved a leg muscle following local stimulation. Foetal lungs were then immediately removed, rinsed in $0.9 \% \mathrm{NaCl}$ solution, frozen in liquid nitrogen and stored at $-80^{\circ} \mathrm{C}$. A lung fragment was fixed in formalin and embedded in paraffin for routine histological examination.

\section{Bacteriological analysis}

Blood withdrawn from all animals at sacrifice was cultured quantitatively by placing $100 \mu \mathrm{L}$ in $800 \mu \mathrm{L}$ of $0.9 \% \mathrm{NaCl}$ solution and $100 \mu \mathrm{L}$ of heparin $\left(5 \mathrm{IU} \cdot \mathrm{mL}^{-1}\right)$. After centrifugation of this mixture at $30,000 \times g$ for $5 \mathrm{~min}, 100 \mu \mathrm{L}$ of the pellet was plated for counts on EMB medium (specific eosinmethylene blue agar; Becton Dickinson, Le Pont de Claix, France). This method allows detection of an inoculum of $1 \times 10^{2} \mathrm{CFU} \cdot \mathrm{mL}^{-1}$.

\section{Assessment of lung inflammation and cell death}

\section{Histology}

Histological evaluation was performed on the lungs of six foetuses in each experimental group. Foetal lungs were removed for histological evaluation. Paraffin sections were stained with haematoxylin-eosin (HE), and inflammation was evaluated according to DNA fragmentation, congestion and the presence of oedema by two independent observers (A. Jarry and C. Toquet, the latter a pathologist).

\section{Cell death}

\section{TUNEL assay}

Cell death was assessed in at least four foetuses in each group, using a terminal deoxynucleotide transferase (TdT)-mediated dUTP nick-end labelling (TUNEL) assay on paraffin sections. The assay was performed using an in situ cell death detection kit (Roche), according to the manufacturer's instructions. Briefly, the sections were deparaffinised, treated for $30 \mathrm{~min}$ at room temperature with $20 \mu \mathrm{g} \cdot \mathrm{mL}^{-1}$ proteinase $\mathrm{K}$ and then with $3 \% \mathrm{H}_{2} \mathrm{O}_{2}$ for 10 min to block endogenous peroxidase, and incubated for $2 \mathrm{~min}$ on ice with $0.1 \%$ Triton $\times 100$ in $0.1 \%$ sodium citrate. DNA strand breaks were visualised by labelling free $3^{\prime}-\mathrm{OH}$ DNA ends with a labelling mixture containing TdT and FITC-labelled nucleotides for $1 \mathrm{~h}$ at $37^{\circ} \mathrm{C}$. Incorporated FITC-nucleotides were detected using an antiFITC antibody conjugated to peroxidase for $30 \mathrm{~min}$ at room temperature, and then a diaminobenzidine (DAB)-substrate solution for $10 \mathrm{~min}$. Slides were slightly counterstained with haematoxylin, dehydrated and mounted. Negative controls were performed by omitting TdT, and positive controls by preincubation with DNase I before the TUNEL assay. In each group of animals, the number of TUNEL-positive cells per field was counted under a microscope $(\times 200$ magnification $)$. At least 15 randomly selected fields were counted per stained section.

\section{Hoechst staining}

The DNA-specific dye Hoechst 33258 (Calbiochem, Merck Biosciences, VWR, Fontenay Sous Bois, France), $1 \mu \mathrm{g} \cdot \mathrm{mL}^{-1}$ in Hank's Balanced Salt Solution without phenol red (Invitrogen, Carlsbad, CA, USA), was used on formalin-fixed paraffin sections of infected and infected-and-treated foetuses $(n=5)$. Sections were mounted with the Prolong Antifade medium (Molecular Probes, Eugene, Oregon, USA). The fluorescence was observed on a fluorescent microscope (Axiovert 200-M; Carl Zeiss, Göttingen, Germany), equipped with an ApoTome slider, which eliminates image blurring. Cells were visualised with a $\times 63 / 1.4$ oil immersion lens. Image processing was performed using an AxioCam MR CCD camera and AxioVision 4.0 software (Carl Zeiss).

\section{Measurement of NOS activity}

Two methodological approaches were used to assess NOS activity in the lungs of infected or infected-and-treated foetuses: 1) measurement of NOS activity based on the conversion of $\left[{ }^{14} \mathrm{C}\right]$-L-arginine into $\left[{ }^{14} \mathrm{C}\right]$-L-citrulline, which allowed the identification of $\mathrm{Ca}^{2+}$-dependent NOS activity (constitutive NOS, i.e. NOS1 or NOS3) or $\mathrm{Ca}^{2+}$-independent inducible NOS activity (NOS2); and 2) histochemical detection of the NADPH diaphorase activity of NOS performed on paraformaldehyde-fixed cryostat sections, which allowed in situ detection of all NOS isoforms.

\section{NOS enzymatic activity}

NOS activity in lung tissue was measured by the conversion of $\left[{ }^{14} \mathrm{C}\right]$-L-arginine monohydrochloride into $\left[{ }^{14} \mathrm{C}\right]$-L-citrulline, as previously described [26]. Briefly, lung tissue was homogenised in a cold buffer containing $50 \mathrm{mM}$ Tris/ $\mathrm{HCl}(\mathrm{pH} 7.5)$, $0.1 \mathrm{mM}$ EDTA and $0.1 \mathrm{mM}$ EGTA, together with the following anti-proteases: $5 \mu \mathrm{g} \cdot \mathrm{mL}^{-1}$ leupeptin, $5 \mu \mathrm{g} \cdot \mathrm{mL}^{-1}$ aprotinin and $0.1 \mathrm{mM}$ Pefabloc (Sigma, Saint Quentin Fallavier, France). Homogenates were centrifuged at $10,500 \times g$ for $1 \mathrm{~h}$, and NOS activity was measured in both supernatants and in pellets solubulised in Tris- $\mathrm{HCl}$ buffer. An aliquot $(25 \mu \mathrm{L})$ was mixed with $100 \mu \mathrm{L}$ of a buffer solution containing $50 \mathrm{mM}$ Tris $/ \mathrm{HCl}$ (pH 7.4), 3 mM NADPH, $75 \mu \mathrm{M} \mathrm{CaCl}, 100 \mathrm{nM}$ calmodulin, 4 $\mu \mathrm{M}$ flavin adenine dinucleotide (FAD; Sigma), $4 \mu \mathrm{M}$ flavin mononucleotide (FMN; Sigma), $6 \mu \mathrm{M}$ tetrahydrobiopterin (BH4; Sigma) and $10 \mu \mathrm{M}\left[{ }^{14} \mathrm{C}\right]$-L-arginine monohydrochloride (NEN Life Science, Perkin Elmer, Wellesley, MA, USA), and then incubated for $10 \mathrm{~min}$ at $37^{\circ} \mathrm{C}$. Stop reaction was promoted by addition of 1-mL stop solution (HEPES Buffer), and the $\left[{ }^{14} \mathrm{C}\right]$-L-arginine monohydrochloride not converted into citrulline was adsorbed on $0.5 \mathrm{~mL}$ of a resin suspension (Dowex 50WX8-400; Aldrich-Sigma, St Quentin Fallavier, France). An aliquot of the supernatant was counted in a $\beta$-scintillation counter (Tricarb 2100 TR; Packard, Perkin Elmer, Wellesley, MA, USA). Activity was expressed as pmol per mg protein per min. Assays were carried out in the absence or presence of $1 \mathrm{mM}$ L-N-arginine methyl ester (L-NAME; Sigma), an inhibitor of all NOS isoforms, or $1 \mathrm{mM}$ EGTA, an inhibitor of $\mathrm{Ca}^{2+}$ dependent NOS. Inducible NOS (NOS2) activity was determined as the difference between NOS activity measured in the presence of L-NAME and EGTA. 


\section{Assessment of the NADPH diaphorase activity of NOS}

In order to localise NOS activity in situ in six foetuses in each group and to avoid technical difficulties inherent to immunohistochemistry in the rabbit, the NADPH diaphorase activity of NOS, which is paraformaldehyde-resistant, was assessed on 5$\mu \mathrm{m}$ cryostat sections fixed in $4 \%$ paraformaldehyde by enzymatic reduction of nitroblue tetrazolium in the presence of NADPH, as previously described [27]. Briefly, slides were incubated in $1 \times$ PBS containing $1 \mathrm{mg} \cdot \mathrm{mL}^{-1} \mathrm{NADPH}$ (Roche) and $0.4 \mathrm{mg} \cdot \mathrm{mL}^{-1}$ nitroblue tetrazolium salt (Roche) for $30 \mathrm{~min}$ at $37^{\circ} \mathrm{C}$, washed in PBS, dehydrated and mounted without any counterstaining. NADPH was omitted in negative controls.

\section{Immunohistochemistry}

In five foetuses in each group, nitrotyrosine residues, indicative of peroxynitrite formation, were assessed on paraffin sections after quenching of endogenous peroxidase with $3 \% \mathrm{H}_{2} \mathrm{O}_{2}$, proteinase $\mathrm{K}$ treatment $(15 \mathrm{~min}$ at room temperature; DakoCytomation, Trappes, France) and nonspecific adsorption with $3 \%$ BSA in PBS for 15 min using a monoclonal anti-nitrotyrosine antibody (1:50 in PBS/1\% BSA, overnight incubation at $4^{\circ} \mathrm{C}$; Zymed, Clinisciences, Montrouge, France). Sections were then incubated with a biotin-conjugated goat anti-mouse antibody (1:200 in PBS/1\% BSA; Santa Cruz Biotechnology, Santa Cruz, CA, USA), followed by streptavidin-biotin-peroxidase complex $(1 \mathrm{~h}$ incubation at room temperature with both agents; Zymed, Clinisciences). $\mathrm{DAB}$ was used as a chromogen and the sections were counterstained with haematoxylin. Negative controls were performed by omitting the primary antibody. Positive controls included human ulcerative colitis and the placenta of infected rabbits.

\section{Statistical analysis}

Data are presented as mean \pm SE. The significance of differences between controls, infected foetuses and infected-and-treated foetuses was evaluated by ANOVA, followed by the Sheffe test. Significance was accepted at $\mathrm{p}<0.05$.

\section{RESULTS}

\section{Survival and bacteraemia}

Without treatment, all mothers died between 24 and $36 \mathrm{~h}$ after infection, in association with septicaemia. In the treated group, all mothers survived. All foetuses in the non-infected (control) group were alive at caesarean section. In the untreated group, after a 12- or 36-h bacterial challenge, the foetal survival rate was 82 and $0 \%$, respectively (fig. 2a). Only foetuses still alive were selected for lung study. Maternal antibiotic therapy, initiated $12 \mathrm{~h}$ after bacterial challenge, enhanced the foetal survival rate, as $67 \%$ of foetuses were still alive after $24 \mathrm{~h}$ of antibiotic treatment, i.e. $36 \mathrm{~h}$ after bacterial challenge (fig. 2a). As previously described [23], bacteraemia was persistent in foetuses despite maternal antibiotic therapy. However, 24-h antibiotic treatment induced significantly lower foetal bacteraemia as compared to non-treated infected foetuses (fig. $2 b$ ).

\section{Analysis of inflammatory response in rabbit foetal lung}

The intensity of the inflammatory response in foetal lungs was assessed using different approaches, including histology, evaluation of cell death, measurement of constitutive and inducible NOS activity, and in situ detection of NOS reductase
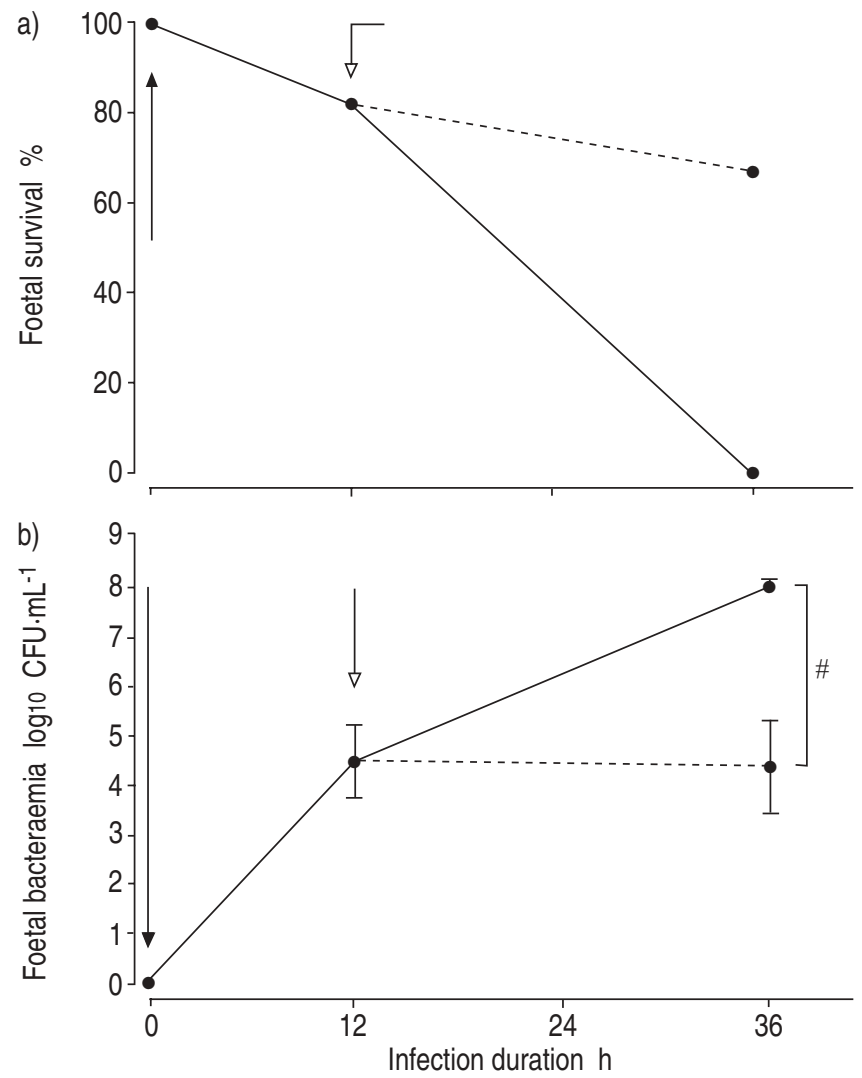

FIGURE 2. Effect of antibiotic treatment on foetal survival and bacteraemia. Twelve hours after intrauterine inoculation of Escherichia coli (arrow), foetuses were treated (----) or not (-) with a combination of ceftriaxone and gentamicin for $24 \mathrm{~h}$ (open arrow: beginning of treatment). a) The percentage of foetal survival expressed by the ratio (living foetuses/total foetuses) $\times 100$. b) Bacteraemia determined in the different foetal groups. ${ }^{\#}: p<0.005$, Scheffe's test after ANOVA.

activity (by NADPH diaphorase histochemistry) and of 3nitrotyrosine residues.

Histological examination of foetal lungs by HE staining after 12-h infection showed moderate inflammation and pulmonary oedema was also observed (fig. 3c). A few neutrophils and macrophages were seen infiltrating septa and alveoli, as well as foci of necrotic/pycnotic nuclei in the mesenchyma. Conversely, after $24 \mathrm{~h}$ of antibiotic treatment, foetal lungs showed almost no signs of inflammation and appeared to be similar to control lungs (fig. $3 \mathrm{a}$ and e). In the three groups examined, i.e. controls, infected and infected-and-treated foetuses, mitotic figures were noted either scattered in the parenchyma or grouped near regions containing pycnotic nuclei.

Cell death, as evaluated by a TUNEL assay on paraffin sections, showed positive nuclei in the mesenchyma or near blood vessels in foci of the infected group, whereas only a few scattered positive nuclei were noted in the infected-and-treated and control groups (fig. 3b, d and f). Accordingly, as shown in figure $3 g$, the number of positive nuclei per field was nearly 10 -fold higher in the infected group than in the infected-andtreated group. 

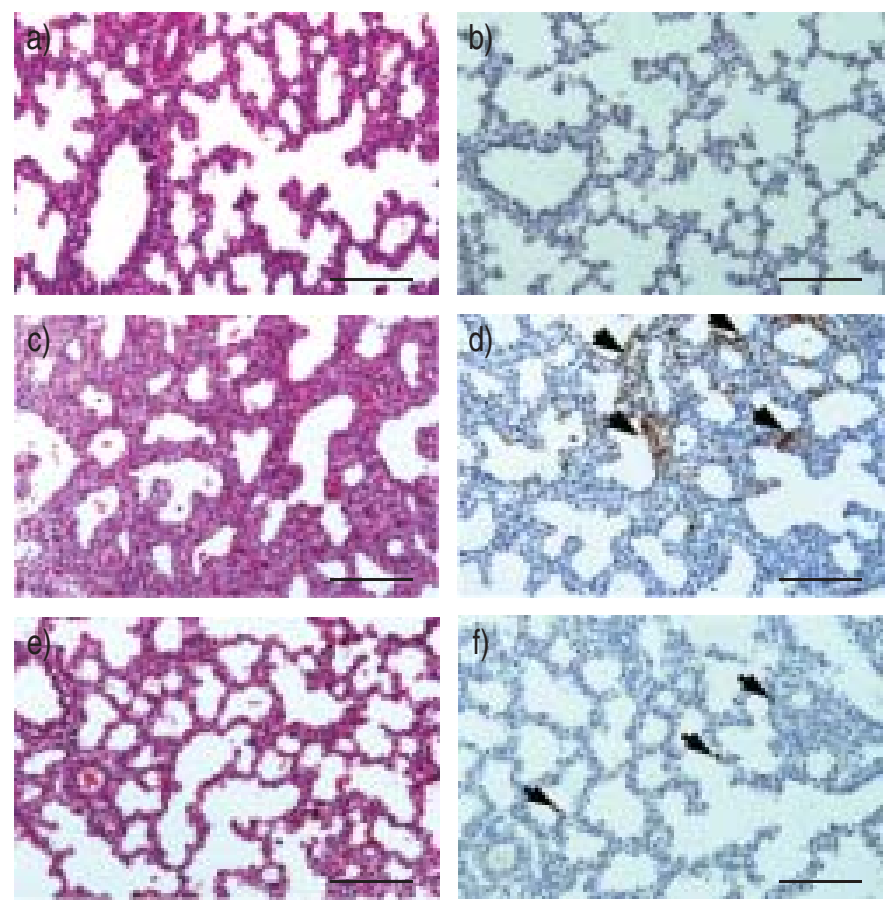

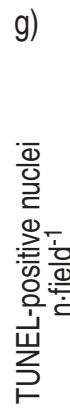
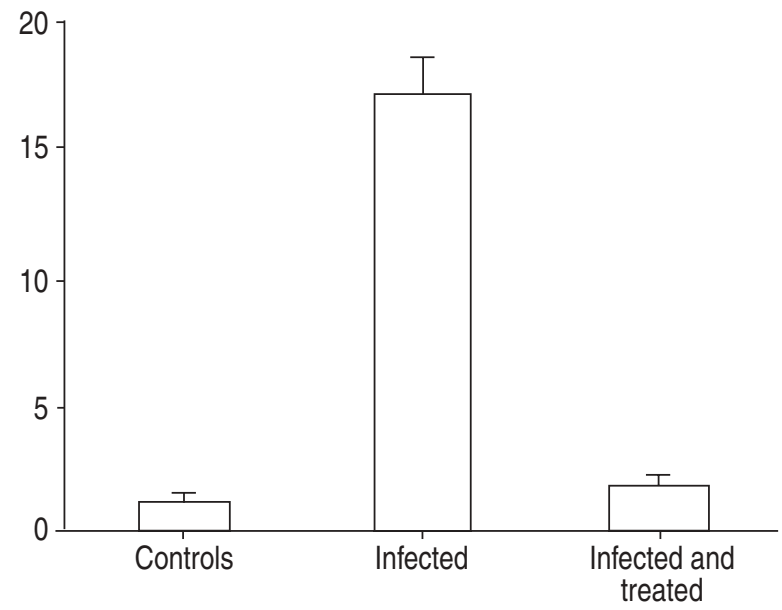

FIGURE 3. Effect of antibiotic treatment on lung inflammation and cell death. Inflammation was assessed on paraffin sections of foetal lungs by haematoxylineosin (HE) staining in the a) control, c) infected and e) infected-and-treated groups. In the infected group, a mild inflammation was observed, with immune cells infiltrating septa and alveoli. Foetal lungs of the infected-and-treated group appeared very similar to the control group. Cell death was detected using a TUNEL assay on paraffin sections of foetal lung in the b) control, d) infected and f) infected-and-treated groups. TUNEL-positive nuclei stained brown (arrows). In the infected group, foci of positive nuclei were noted in the mesenchyma. However, only rare TUNEL-positive cells were observed near the septa in the infected-andtreated and in the control groups. Internal scale bar $=150 \mu \mathrm{m}$. g) Evaluation of the number of TUNEL-positive cells in lungs of control, infected, and infected-andtreated foetuses. Data are presented as mean \pm SE of four foetuses in each group. A significant decrease in TUNEL-positive nuclei was found in the infected-and-treated group when compared with the infected control group $(p<0.001)$.

In addition, in the infected group cells, staining with Hoechst 33258 dye on serial sections showed chromatin condensation and fragmentation, and apoptotic bodies characteristic of full-blown apoptosis in the same areas as those containing
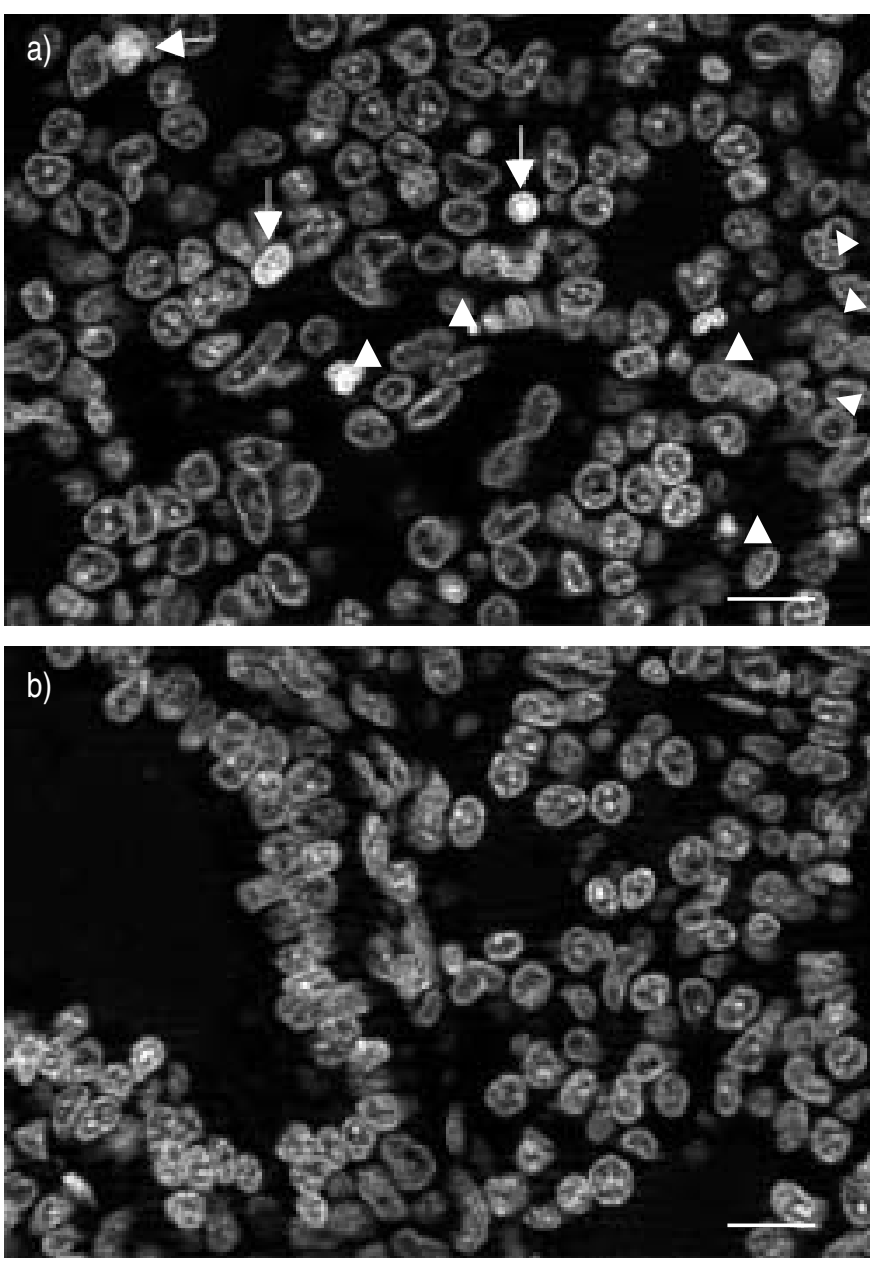

FIGURE 4. Analysis of cell death by Hoechst staining in the a) infected and b) infected-and-treated groups. Chromatin condensation (arrows) and apoptotic bodies (arrowheads), characteristic of full-blown apoptosis, were observed in the mesenchyma in the infected group. By contrast, the majority of cells in the infectedand-treated group displayed a normal nuclear morphology. Internal scale $\mathrm{bar}=15 \mu \mathrm{m}$.

TUNEL-positive cells (fig. 4a). By contrast, only very few cells displayed chromatin condensation in the infected-and-treated group (fig. 4b) and in the control group.

$\mathrm{Ca}^{2+}$-dependent constitutive NOS activity and $\mathrm{Ca}^{2+}$ independent inducible NOS activity were measured in foetal lungs of control, infected, and infected-and-treated foetuses. Bacterial challenge induced a significant decrease in constitutive $\mathrm{Ca}^{2+}$-dependent NOS activity, which was restored to control levels after $24 \mathrm{~h}$ of antibiotic therapy (fig. 5a). Control foetuses displayed very low inducible $\mathrm{Ca}^{2+}$-independent NOS activity (NOS2), which was significantly increased in the infected group and returned to basal levels after $24 \mathrm{~h}$ of antibiotic therapy (fig. 5b).

The NADPH activity of NOS was assessed in situ on paraformaldehyde-fixed cryostat sections. In control foetuses $(n=3)$, blood vessels displayed NADPH diaphorase activity in endothelial cells and smooth muscle vascular cells. Epithelial cells of secondary bronchi scored weakly positive and pneumocytes underlying alveoli appeared to be negative. 

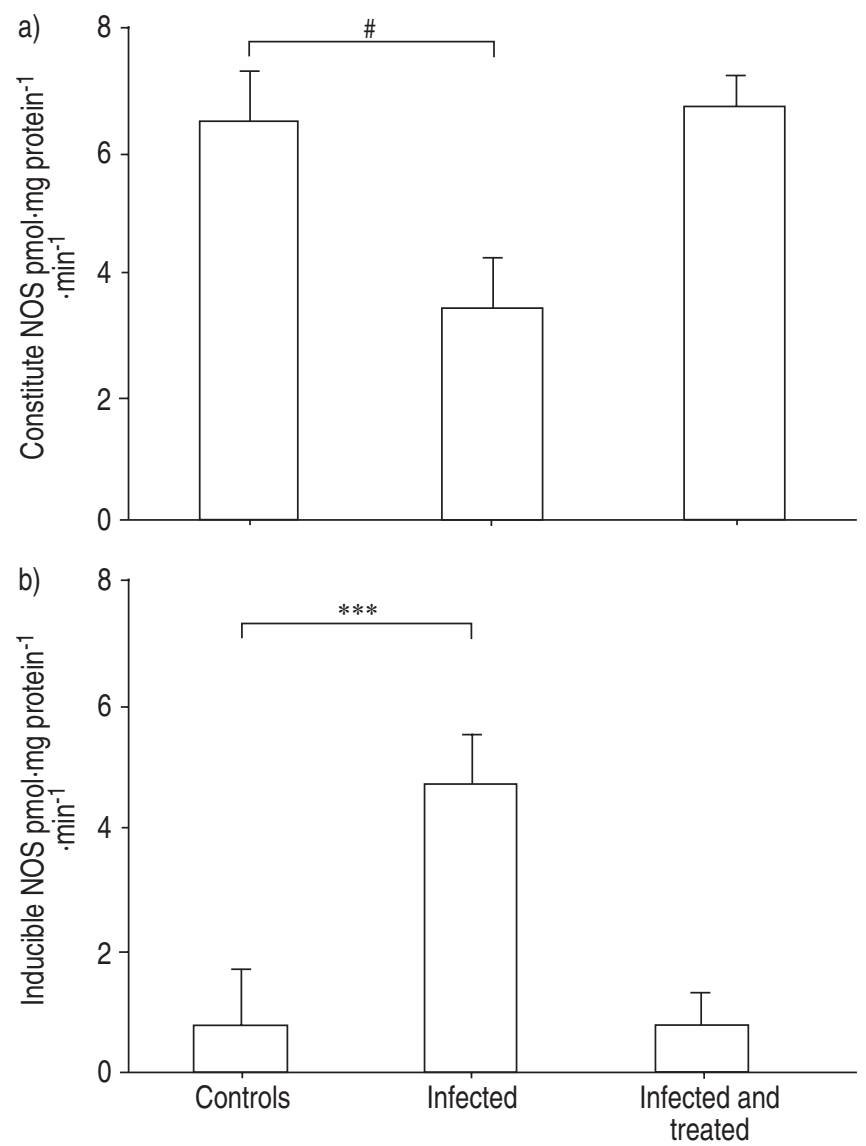

FIGURE 5. a) Constitutive and b) inducible nitric oxide synthase (NOS) activities. Data are presented as mean \pm SE of $10-15$ foetuses from two or three mothers. ${ }^{*}: p=0.007 ; * * *: p=0.001$.

Pulmonary mesenchyma did not express any NADPH diaphorase activity. In infected foetuses $(n=4)$, NADPH diaphorase activity was much higher, being detectable not only in blood vessels but also in epithelial cells of secondary bronchi and alveolar pneumocytes. Immune cells (mainly macrophages) in the mesenchymal infiltrate and the alveolar lumen expressed strong NADPH diaphorase activity. In infected-and-treated foetuses $(n=6)$, NADPH diaphorase activity was still observed in secondary bronchi and in some pneumocytes, but was almost absent in the parenchyma (fig. 6).

The presence of 3-nitrotyrosine residues in the infected group was detected in a few mesenchymal cells and in macrophages within the alveolar lumen, as well as in the epithelium of secondary bronchi and of some alveolar pneumocytes. Interestingly, 3-nitrotyrosine residues were often present in TUNEL-positive cells as assessed on serial sections. Conversely, 3-nitrotyrosine residues were barely detectable in infected-and-treated foetuses and in the control group (fig. 7).

\section{DISCUSSION}

This study, in an experimental model of rabbit E. coli maternofoetal infection, provides the first in vivo evidence that: 1) prenatal infection induces an inflammatory response in the foetal lung, causing NO-derived oxidative stress and programmed cell death; and 2) that early antibiotic therapy can limit this inflammatory response, and decrease infectioninduced oxidative stress and cell death, although the bacterial load persists. These findings, which bring new insights into the effects of antibiotic therapy, may have implications for the understanding of the pathophysiological mechanisms leading to antenatal lung injury.

First, this study shows that NO-derived species are important components of an early foetal pulmonary inflammatory response elicited by $E$. coli infection. It is noteworthy that the inflammatory response in the current model remained moderate, due to the short period of exposure to infection (12 h), which was chosen because of the very high mortality observed beyond that time-point in the absence of treatment. Different and complementary methodological approaches indicated that inducible NOS activity increases in the early phase of inflammation, resulting in the formation of RNS, as revealed by the formation of 3-nitrotyrosine residues. In addition to biochemical measurements of NOS activity, in situ localisation of NOS activity (by NADPH diaphorase histochemistry) and 3nitrotyrosine residues showed that epithelial cells of the secondary bronchi and alveolar pneumocytes, as well as immune cells present in the mesenchyma, are a source of inducible NOS and ROS. These results are consistent with the
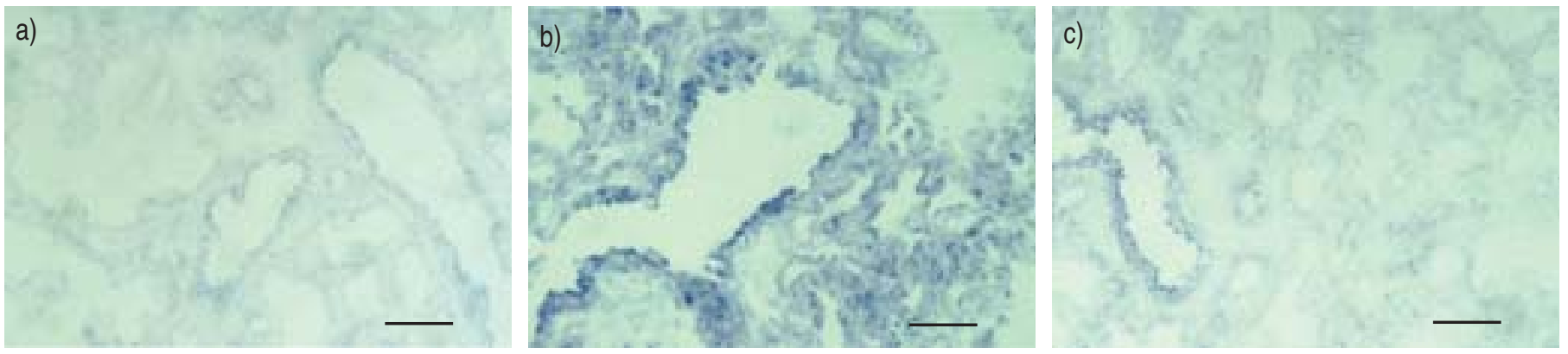

FIGURE 6. Localisation of the NADPH diaphorase activity of nitric oxide synthase in a) control, b) infected and c) infected-and-treated groups. NADPH diaphorase activity appears as a blue precipitate. In the infected group, a strong staining was observed in epithelial cells of the secondary bronchi and alveoli, as well as in the mesenchyma. In the infected-and-treated group, NADPH diaphorase staining was strong in the secondary bronchi epithelial cells but weak or absent in alveoli, and absent in the mesenchyma. Internal scale bar $=100 \mu \mathrm{m}$ 

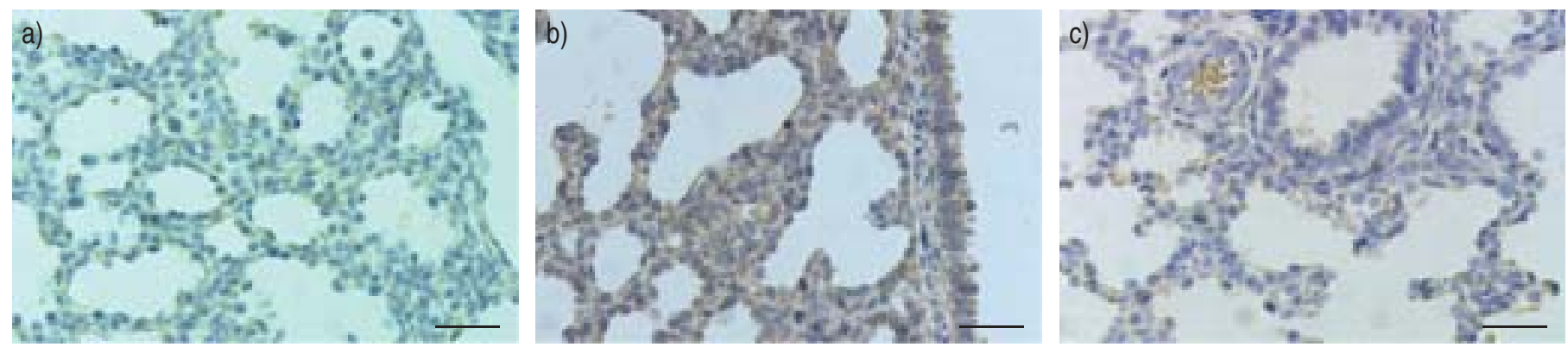

FIGURE 7. Localisation of nitrotyrosine residues in lungs of a) control, b) infected and c) infected-and-treated groups. No nitrotyrosine residues (brown cytoplasmic staining) were detected in the control group. In the infected group, intense staining was seen in the epithelial cells of secondary bronchi and in the mesenchyma. However, in the infected-and-treated group, only a few positive cells were present in the mesenchyma. Internal scale bar $=50 \mu \mathrm{m}$.

findings of previous reports in which 3-nitrotyrosine residues were found to be involved in the development of BPD in premature infants [19].

This study also suggests that nitrosative stress, resulting from RNS, in infected foetuses is associated with programmed cell death. Most of the cells undergoing cell death in this study possessed 3-nitrotyrosine residues, which suggests an association between the two processes involved in cell death and lung injury. In line with these findings, recent in vivo and in vitro experiments have strongly suggested that the formation of nitrating species or protein tyrosine nitration plays a significant role in the apoptotic process [28, 29]. In addition, it has been shown that apoptosis is implicated in the development of BPD [10] and respiratory distress syndrome [30]. In order to demonstrate the direct effect of $\mathrm{NO}$ in the foetal lung lesions observed here, further studies, using, for example, specific inducible NOS inhibitors successfully tested in septic shock [31, 32], could be performed.

In addition, the increase in inducible NOS was accompanied, in infected foetuses, by a decrease in constitutive NOS. These findings are consistent with previous reports in animal models or in humans showing that septic shock resulted in a decrease of constitutive NOS [33] or an increase in inducible NOS [34]. This decrease of constitutive NOS, produced in foetal lungs in part by endothelial cells, could have vasoconstrictive effects on lung vessels, leading to poor adaptation to extrauterine life and causing neonatal hypoxia in infected newborns $[35,36]$.

A key finding of this study is that antibiotic therapy, initiated as early as $12 \mathrm{~h}$ after bacterial challenge, is associated with a significant decrease in infection-induced oxidative stress and subsequent cell death, thus suggesting a protective role of antibiotics by modulating the inflammatory response despite the persistence of bacterial load. This rapid decrease in cell death after $24 \mathrm{~h}$ of antibiotic therapy may be due to the clearance of apoptotic cells by macrophages and subsequent cell proliferation. This phenomenon could represent an enhancement of the physiological balance between cell death and cell proliferation in foetal lungs [37, 38]. The current findings indicate that antibiotic treatment administered early after disease onset can curb the inflammatory reaction. Nevertheless, this free interval before more marked expression of inflammation could constitute a therapeutic window for early treatment and limitation of the deleterious effects of inflammation.
One limit of this acute model is that infected animals could not survive without antibiotics for more than $36 \mathrm{~h}$, therefore, making it difficult to distinguish clearly the relative contribution of antibiotic therapy and host response in the resolution of inflammation $36 \mathrm{~h}$ after E. coli inoculation. Different mechanisms could be involved in the maternal antibiotic therapy effects that can act on both components of host infectious disease by: 1) reducing bacterial growth and subsequent inoculum size; and 2) limiting inflammatory response. Three types of mechanisms may be involved: first, antibiotics could exert an indirect effect on inflammatory response by limiting bacterial growth, virulence and pathogenicity; secondly, antibiotics that sterilise maternal blood culture could limit maternal cytokine production, thereby decreasing foetal inflammatory response; and finally, antibiotic therapy could have a direct action on the inflammatory response. Indeed, gentamicin has been shown to inhibit superoxide generation in human activated neutrophils in vitro [39] and to act directly on airway epithelial cells by restoring cell function in cystic fibrosis patients [40]. This last hypothesis warrants further studies to determine the mechanisms involved in the pharmacological effects of ceftriaxone and gentamicin in this model. An understanding of the precise mechanisms of action of antibiotics on foetal lung injury would allow the development of therapeutic strategies to limit the antenatal injury possibly involved in bronchopulmonary dysplasia and chronic lung disease.

\section{REFERENCES}

1 Ohyama M, Itani Y, Yamanaka M, et al. Re-evaluation of chorioamnionitis and funisitis with a special reference to subacute chorioamnionitis. Hum Pathol 2002; 33: 183-190.

2 Watterberg KL, Demers LM, Scott SM, Murphy S. Chorioamnionitis and early lung inflammation in infants in whom bronchopulmonary dysplasia develops. Pediatrics 1996; 97: 210-215.

3 Yoon BH, Romero R, Jun JK, et al. Amniotic fluid cytokines (interleukin-6, tumor necrosis factor- $\alpha$, interleukin- $1 \beta$, and interleukin-8) and the risk for the development of bronchopulmonary dysplasia. Am J Obstet Gynecol 1997; 177: 825-830.

4 Jobe AH, Ikegami M. Antenatal infection/inflammation and postnatal lung maturation and injury. Respir Res 2001; 2: $27-32$. 
5 Sobel DB, Carroll A. Postsurfactant slump: early prediction of neonatal chronic lung disease? I Perinatol 1994; 14 268-274.

6 Yoon BH, Romero R, Kim KS, et al. A systemic fetal inflammatory response and the development of bronchopulmonary dysplasia. Am J Obstet Gynecol 1999; 181: 773-779.

7 Davis JM, Rosenfeld W. Chronic lung disease. In: Avery GB, Fletcher MA, McDonald MD, eds. Neonatology. J.B. Lippincott, Philadelphia, 1999; pp. 509-532.

8 Schmidt B, Cao L, Mackensen-Haen S, Kendziorra H, Klingel K, Speer CP. Chorioamnionitis and inflammation of the fetal lung. Am J Obstet Gynecol 2001; 185: 173177.

9 Davis JM. Role of oxidant injury in the pathogenesis of neonatal lung disease. Acta Paediatr 2002; 91: Suppl. 437, 23-25.

10 Hargitai B, Szabo V, Hajdu J, et al. Apoptosis in various organs of preterm infants: histopathologic study of lung, kidney, liver, and brain of ventilated infants. Pediatr Res 2001; 50: 110-114.

11 Gomez R, Romero R, Ghezzi F, Yoon BH, Mazor M, Berry SM. The fetal inflammatory response syndrome. Am J Obstet Gynecol 1998; 179: 194-202.

12 Kotecha S, Wilson L, Wangoo A, Silverman M, Shaw RJ. Increase in interleukin (IL)-1 $\beta$ and IL-6 in bronchoalveolar lavage fluid obtained from infants with chronic lung disease of prematurity. Pediatr Res 1996; 40: 250-256.

13 Speer CP. Inflammation and bronchopulmonary dysplasia. Semin Neonatol 2003; 8: 29-38.

14 Kinnula VL, Crapo JD, Raivio KO. Generation and disposal of reactive oxygen metabolites in the lung. Lab Invest 1995; 73: 3-19.

15 Hausladen A, Stamler JS. Nitrosative stress. Methods Enzymol 1999; 300: 389-395.

16 Griffith OW, Stuehr DJ. Nitric oxide synthases: properties and catalytic mechanism. Ann Rev Physiol 1995; 57: 707-736.

17 Alderton WK, Cooper CE, Knowles RG. Nitric oxide synthases: structure, function and inhibition. Biochem J 2001; 357: 593-615.

18 Wink DA, Grisham MB, Miles AM, et al. Determination of selectivity of reactive nitrogen oxide species for various substrates. Methods Enzymol 1996; 268: 120-130.

19 Banks BA, Ischiropoulos $\mathrm{H}$, McClelland $\mathrm{M}$, Ballard $\mathrm{PL}$ Ballard RA. Plasma 3-nitrotyrosine is elevated in premature infants who develop bronchopulmonary dysplasia. Pediatrics 1998; 101: 870-874.

20 MacRitchie AN, Albertine $\mathrm{KH}$, Sun J, et al. Reduced endothelial nitric oxide synthase in lungs of chronically ventilated preterm lambs. Am J Physiol l 2001; 281: L1011-L1020.

21 Hopkins L, Smaill F. Antibiotic regimens for management of intraamniotic infection. Cochrane Database Syst Rev 2002 CD003254.

22 Gibbs RS, Davies JK, McDuffie RS Jr, et al. Chronic intrauterine infection and inflammation in the preterm rabbit, despite antibiotic therapy. Am J Obstet Gynecol 2002; 186: 234-239.

23 Gras-Le Guen C, Debillon T, Toquet C, et al. Persistent bacteremia in rabbit fetuses despite maternal antibiotic therapy in a novel intrauterine-infection model. Antimicrob Agents Chemother 2003; 47: 2125-2130.

24 Bingen E, Bonacorsi S, Brahimi N, Denamur E, Elion J. Virulence patterns of Escherichia coli K1 strains associated with neonatal meningitis. J Clin Microbiol 1997; 35 2981-2982.

25 Bugnon D, Potel G, Caillon J, et al. In vivo simulation of human pharmacokinetics in the rabbit. Bull Math Biol 1998; 60: 545-567.

26 Bredt DS, Snyder SH. Nitric oxide mediates glutamatelinked enhancement of cGMP levels in the cerebellum. Proc Natl Acad Sci USA 1989; 86: 9030-9033.

27 Weinberg RJ, Valtschanoff JG, Schidt HHW. The NADPH diaphorase histochemical stain. In: Feelisch, Stamler JS, eds. Methods in Nitric Oxide Research. John Wiley and Sons, UK, 1996; pp. 237-248.

28 Moulian N, Truffault F, Gaudry-Talarmain YM, Serraf A, Berrih-Aknin S. In vivo and in vitro apoptosis of human thymocytes are associated with nitrotyrosine formation. Blood 2001; 97: 3521-3530.

29 Ischiropoulos H. Biological selectivity and functional aspects of protein tyrosine nitration. Biochem Biophys Res Commun 2003; 305: 776-783.

30 Lukkarinen HP, Laine J, Kaapa PO. Lung epithelial cells undergo apoptosis in neonatal respiratory distress syndrome. Pediatr Res 2003; 53: 254-259.

31 Neviere R, Fauvel H, Chopin C, Formstecher P, Marchetti P. Caspase inhibition prevents cardiac dysfunction and heart apoptosis in a rat model of sepsis. Am J Respir Crit Care Med 2001; 163: 218-225.

32 Scott JA, McCormack DG. Selective in vivo inhibition of inducible nitric oxide synthase in a rat model of sepsis. J Appl Physiol 1999; 86: 1739-1744.

33 Zhou M, Wang P, Chaudry IH. Endothelial nitric oxide synthase is downregulated during hyperdynamic sepsis. Biochim Biophys Acta 1997; 1335: 182-190.

34 Kilbourn RG, Griffith OW. Overproduction of nitric oxide in cytokine-mediated and septic shock. J Natl Cancer Inst 1992; 84: 827-831.

35 Abman SH, Chatfield BA, Hall SL, McMurtry IF. Role of endothelium-derived relaxing factor during transition of pulmonary circulation at birth. Am J Physiol 1990; 259: H1921-H1927.

36 Xue C, Reynolds PR, Johns RA. Developmental expression of NOS isoforms in fetal rat lung: implications for transitional circulation and pulmonary angiogenesis. Am J Physiol 1996; 270: L88-L100.

37 De Paepe ME, Sardesai MP, Johnson BD, LesieurBrooks AM, Papadakis K, Luks FI. The role of apoptosis in normal and accelerated lung development in fetal rabbits. J Pediatr Surg 1999; 34: 863-870.

38 Kresch MJ, Christian C, Wu F, Hussain N. Ontogeny of apoptosis during lung development. Pediatr Res 1998; 43: 426-431.

39 Umeki S. Inflammatory action of gentamycin through inhibitory effect on neutrophil NADPH oxidase activity. Comp Biochem Physiol B Biochem Mol Biol 1995; 110: 817-821.

40 Wilschanski M, Yahav Y, Yaacov Y, et al. Gentamicininduced correction of CFTR function in patients with cystic fibrosis and CFTR stop mutations. N Engl J Med 2003; 349: 1433-1441. 